\title{
B01
}

\section{Empirical Correlations to Shale Strength}

\section{D.N Dewhurst* (CSIRO Petroleum), C. Delle Piane (CSIRO Petroleum), M.B. Clennell (CSIRO Petroleum), M. Josh (CSIRO Petroleum), M.D. Raven (CSIRO Land \& Water) \& A.F. Siggins (CSIRO Petroleum)}

\section{SUMMARY}

A suite of preserved shales from basins widely separated in space and time underwent multi-stage triaxial tests in the laboratory to evaluate static and dynamic mechanical properties. Coupled with these tests was a workflow for extensive characterisation of physical and petrophysical properties, including porosity, bulk density, specific surface area, electrical properties and microstructural evaluation. Good correlations have been found between shale strength (cohesion and unconfined compressive strength) and some physical properties and there are encouraging relationships between dielectric properties and both static and dynamic mechanical properties. Poor relationships were found to friction coefficient and also between properties previously thought good for predicting shale strength, such as P-wave velocity. 


\section{Fault and Top Seals \\ Montpellier 2009}

\section{Introduction}

Shales as top seals are often the neglected part of the petroleum system in terms of characterisation of rock properties. However, in recent years, interest has been sparked in shale properties with the understanding that knowledge of shale behaviour can save tens of millions of dollars in applications such as seal evaluation, pore pressure prediction, wellbore stability and 4D seismic data (e.g. Stjern et al., 2003). However, shale cores are rarely recovered and even when they are, they are not often preserved during storage to ensure no loss of pore fluid which can alter rock properties through desiccation and fracturing. As such, sparse information is available concerning physical properties and geomechanical behaviour of these rocks. The rationale behind this work was to try to relate geomechanical properties measured in the laboratory to more easily measured physical and/or petrophysical properties to allow extrapolation though a top seal interval.

\section{Results}

Given that the shales tested are widely separated in space and time, some promising correlations were obtained. Cation exchange capacity (CEC) normalised to clay fraction showed reasonable correlation to both cohesion and UCS. The correlation to UCS is shown in Figure 1a. Similarly, porosity is also shown to have a good correlation with UCS (Figure 1b) and these data include samples tested in this project plus a number of data points taken from the literature where sufficient care had been taken to preserve the samples before testing. Dried samples from the literature were specifically excluded due to the changes in physical and geomechanical properties induced by this process.

Velocity has regularly been used as a predictor of rock strength in the past. Ultrasonic velocity and anisotropy data from these shales were investigated as predictors of rock strength. Neither velocity nor anisotropy appeared to correlate well with friction or strength properties. However, factors such as lithology and porosity also affect velocity, so we used Pwave impedance normalised to clay content to try to account for some of the scatter in the velocity data. This did improve $\mathrm{R}^{2}$ values but only to $\sim 0.7$.

Friction coefficient has usually proved difficult to correlate with standard physical properties and while there are claimed correlations in the literature, no details have actually been published. This study has also shown that it is difficult to find single parameters that correlate well, or in fact even at all, with friction coefficient (Figure 2). Two of the most likely parameters that one might have thought would have a reasonable correlation with friction, clay content (Figure 2a) and porosity (Figure $2 b$ ), show almost completely random scatter. The best single variable correlations that could be obtained were with P-wave velocity and its anisotropy, as well as $\mathrm{V}_{\mathrm{p}} / \mathrm{V}_{\mathrm{s}}$ ratio, but all of these were $<0.4$ ! This suggests that micromechanical mechanisms at grain boundaries may be more important than bulk rock properties in terms of controlling friction coefficient. 


\section{raulaum to s seals \\ Montpellier 2009}
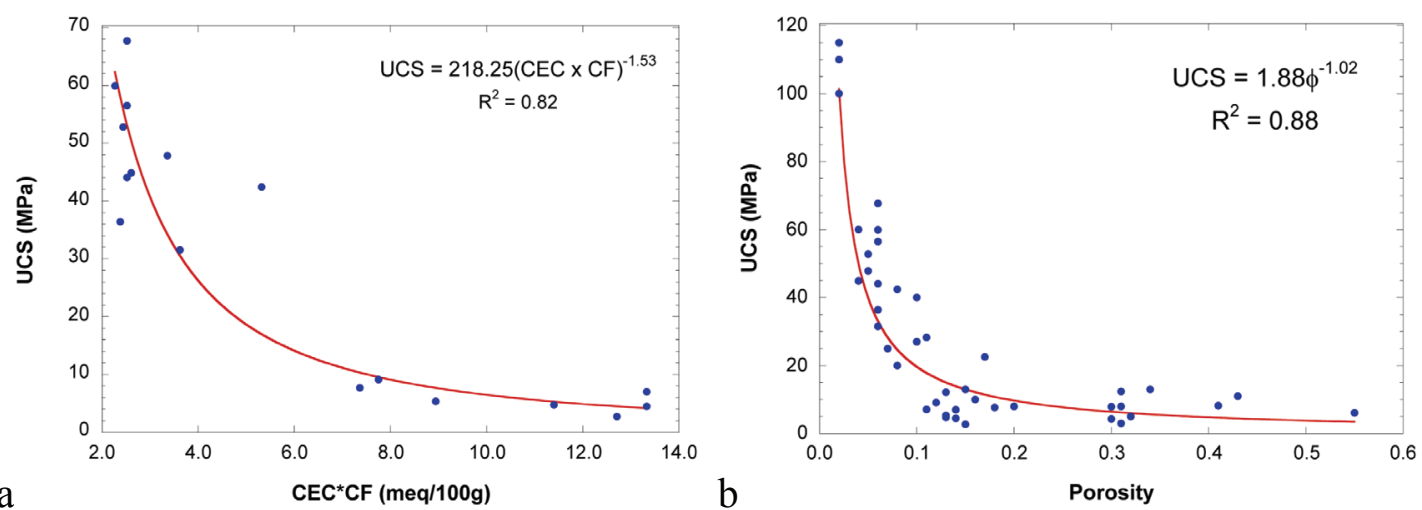

Figure 1 (a) Correlation between normalised cation exchange capacity and shale unconfined compressive strength from shales tested in this project; (b) correlation between porosity and unconfined compressive strength from shales tested in this project and preserved shale data taken from the literature (e.g. Horsrud et al., 2001).
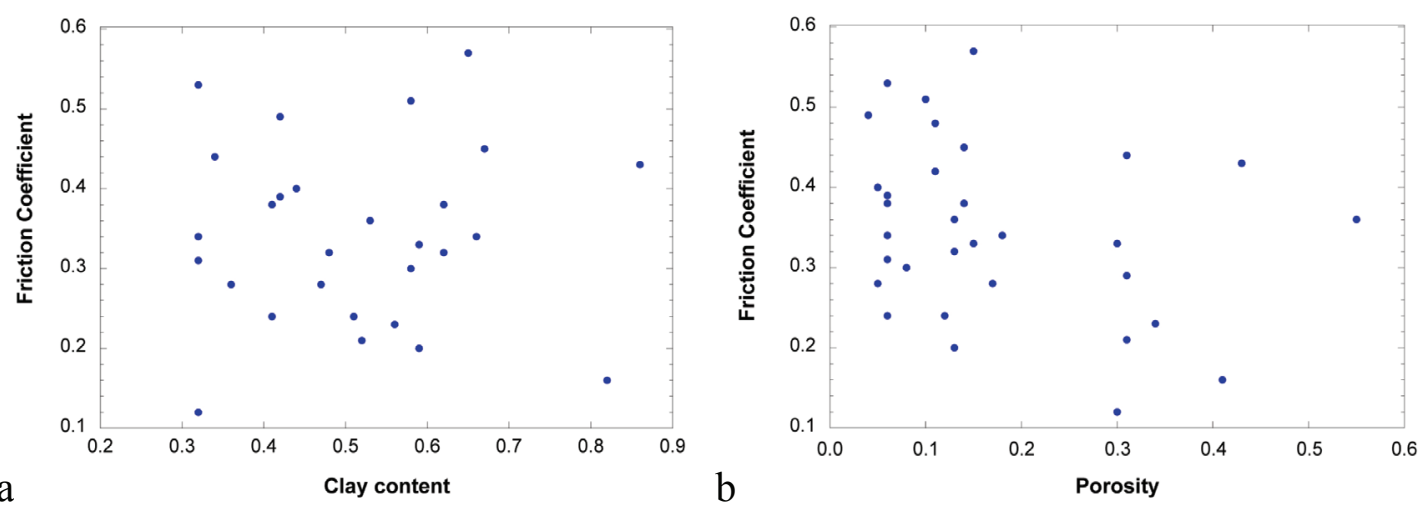

Figure 2 (a) Lack of correlation between clay content and friction coefficient from shales tested in this project; (b) Lack of correlation between porosity and friction coefficient from shales tested in this project.

Encouraging correlations, admittedly from a currently sparse data set have been found between dielectric response and shale strength properties. In addition, very good correlations were found between dielectric behaviour and some static (e.g. Young's Modulus) and dynamic (e.g. P-wave velocity) mechanical properties.

\section{Conclusions}

A suite of shale ranging in age from Proterozoic to Tertiary and spatially widespread from the North Sea to the Australian margin has been characterised and empirical correlations derived to strength parameters. Reasonable correlations to UCS and cohesion have been obtained for this global dataset, although friction coefficient remains elusive. Further work is in progress using more complex statistical techniques to analyse the data.

\section{References}

Stjern, G., A. Agle,. and P. Horsrud, 2003, Local rock mechanical knowledge improves drilling performance in fractured formations at the Heidrun field. Journal of Petroleum Science and Engineering, 38, 83-96.

Horsrud P, 2001, Estimating mechanical properties of shale from empirical correlations. SPE Drilling and Completion, 16, 68-73. 